\title{
Molecular genetics of familial hypertrophic cardiomyopathy (FHC)
}

\begin{abstract}
Familial hypertrophic cardiomyopathy is an autosomal dominant disease with a wide range of clinical features from benign to severe, and is the most common cause of sudden death in otherwise healthy individuals. The two prominent clinical features are left ventricular hypertrophy and myocyte/myofibrillar disarray. The former is responsible for clinical symptoms such as breathlessness and angina, whereas the latter may lead to sudden cardiac death. The last decade has seen an enormous improvement in our understanding of the molecular genetics of this disorder. The clinical heterogeneity has been linked to genetic heterogeneity; mutations in nine genes encoding sarcomere proteins have been shown to be the molecular basis for the disorder. However, attempts to establish a genotype-phenotype correlation for each of the more than 100 mutations that have been identified have not been highly successful. Additional genetic loci, as well as nongenetic factors such as lifestyle, sex, and age, have also been shown to play a role in modulating the clinical presentation of the disease. How each mutation results in hypertrophy and/or myofibrillar disarray is unclear. The present review discusses the current status of the molecular genetic characterization of this important disorder.
\end{abstract}

Key words Hypertrophy · Cardiomyopathy · Myosin · Troponin $\cdot$ Tropomyosin $\cdot$ Actin $\cdot$ Myocyte disarray

M.D. Bashyam $(\bowtie) \cdot$ M.S. Kumar

Molecular Oncology, Centre for DNA Fingerprinting and

Diagnostics (CDFD), Nacharam, Hyderabad 500076, India

Tel. +91-40-7150008; Fax +91-40-7155610

e-mail: bashyam@www.cdfd.org.in

G.R. Savithri

Laboratory of Molecular and Cellular Biology, Centre for DNA

Fingerprinting and Diagnostics (CDFD), Hyderabad, India

C. Narasimhan

Care Hospital, Hyderabad, India

P. Nallari

Department of Genetics, Osmania University, Hyderabad, India

\section{Introduction}

Familial hypertrophic cardiomyopathy (FHC) is an autosomal dominant disease characterized mainly by left ventricular hypertrophy. The left ventricular architecture in FHC is disorganized, with hypertrophic cardiac myocytes having abnormal shapes and multiple intercellular connections and being arranged in a chaotic pattern (myocyte disarray). Myocyte loss and replacement fibrosis are prominent features (Davies 1994; Maron et al. 1987), which can result in arrhythmia and altered myocardial hemodynamics. The term "hypertrophy" denotes a thickening of tissue due to an increase in the size of the constituent cells. The term "cardiomyopathy" means a disease of heart muscle (cardio, heart; myo, muscle; pathy, disease). Hypertrophy, in general, is recognized as a compensatory thickening of the left ventricle wall that occurs as a physiologic response to either excessive hemodynamic burden (such as pressure or volume overload due to hypertension and aortic valve disease) or a pathologic state that compromises function of the heart muscle (Grossman et al. 1975). FHC however, is a heritable disorder that occurs in the absence of hemodynamic burden. FHC is the most common cause of sudden death in otherwise healthy young individuals (Maron et al. 1978, 1986). The frequency of hypertrophic cardiomyopathy is approximately $0.1 \%-0.2 \%$ in Europe and the United States. The genetic basis for this disorder has been shown to be mutations in the cardiac sarcomere protein-coding genes. However, it is not clear how these mutations actually induce the hypertrophic response in the heart. Efforts are underway also to establish a genotype-phenotype correlation for this disorder.

\section{Clinical symptoms}

The disease is characterized by extreme clinical and morphological heterogeneity, ranging from benign to severe, and is further complicated by a variable age of presentation. 
Clinically, the patients may present with some or all of the following symptoms.

\section{Dyspnea (breathlessness)}

Dyspnea is usually linked to physical activity but occasionally may manifest even at rest and may be more pronounced following meals. Shortness of breath results from an elevation of left ventricular diastolic pressure due to the thickening of the ventricle wall, and this increased pressure is relayed to the lungs via the pulmonary capillaries, leading to pulmonary congestion characterized clinically by dyspnea.

\section{Chest pain}

Also called angina, chest pain is a common symptom. It is usually brought on by exertion and relieved by rest, but may also occur at rest or during sleep and may persist. The greatly thickened muscle demands an increased oxygen supply and chest pain results when this demand cannot be met.

\section{Syncope (fainting)}

Patients may experience light-headedness, dizziness, and, more seriously, blackouts. Presyncope denotes dizziness, but the patient does not pass out completely. Episodes may occur in association with exercise, with palpitations, or without any apparent association. Fainting episodes may be due to an irregularity of the heartbeat, or a fall in blood pressure leading to insufficient blood supply to the brain.

\section{Palpitations}

Patients may occasionally feel an extra beat or a skipped beat, suggesting an irregular heart rhythm. Palpitations may start suddenly, may appear to be very fast, and may be associated with sweating or light-headedness.

\section{Arrhythmias}

Arrhythmias are irregularities of the heartbeat, which occur because of disruption of the electrical conduction system of the heart. Myocyte disarray may be the primary cause for this disruption. Two types of arrhythmias, namely, ventricular tachycardia (arising from the ventricles) and atrial fibrillation (occurring in the atria) are particularly important and may require treatment. In atrial fibrillation, the normal regular rhythm of the heartbeat is lost and is replaced by an irregular rhythm that may be episodic (paroxysmal atrial fibrillation) or persistent. The loss of normal atrial contraction produces a risk of clot formation in the auricle. Sometimes the heart may need to be shocked back into normal rhythm. Heart block may result if the normal electrical signal travels down to the ventricles slowly or is completely blocked. This is uncommon, but if this occurs, a pacemaker may be required. The importance of FHC stems from the fact that a large number of patients may have an increased risk of premature death (due to arrhythmia), which may occur with little or no warning. Ventricular fibrillations usually precede sudden death.

\section{Hypertrophy}

The characteristic feature of FHC is the hypertrophied heart. However, there is a high degree of variability in the location and kind of hypertrophy. It could be concentric (spread throughout the left ventricle wall), apical (only the base of the left ventricle), or septal (affecting only the septum). There is an additional complication associated with septal hypertrophy. If hypertrophy occurs in the proximal region of the septum, the inward movement of the hypertrophied septum during systole pulls the anterior leaflet of the mitral valve toward the septum (SAM, systolic anterior motion), causing obstruction in the left ventricular outflow tract. Obstruction may also be a result of the septum thickening itself but is accentuated by SAM. SAM can sometimes be diagnosed by listening to a "murmur" sound in the heartbeat. SAM may also result in flow of blood back into the left atrium from the left ventricle, which is termed "mitral regurgitation."

\section{Diagnosis}

Clinically, FHC is diagnosed based on the medical history, physical examination, and electrocardiographic and echocardiographic identification of the septal and left ventricular hypertrophy. The electrocardiogram (ECG) usually shows an abnormal electrical signal due to muscle thickening and disorganization of the muscle structure. In a minority of patients $(5 \%-10 \%)$, however, the ECG may be normal or show only minor changes. ECG abnormalities are not specific to FHC and may be encountered in other heart conditions as well. An accurate diagnosis of FHC is therefore based on an ultrasound scan of the heart called an echocardiogram (Echo). The Echo produces a picture of the heart in which excessive thickness of the muscle can be easily measured. Additional equipment called Doppler ultrasound can produce a color image of blood flow within the heart and measure the heart's contraction and filling. Turbulent flow inside the heart can also be detected by this method.

\section{Genetic basis of FHC}

Myofibrils, which consist of repeating units known as sarcomeres, make up the contractile elements in muscle. A sarcomere consists of seven major proteins and several minor proteins organized into thick and thin filaments. Thick filaments comprise myosin heavy and light chains and the 
Table 1. FHC disease genes and mutation frequencies

\begin{tabular}{llll}
\hline Gene name & $\begin{array}{l}\text { Gene } \\
\text { symbol }\end{array}$ & $\begin{array}{l}\text { Chromosomal } \\
\text { location }\end{array}$ & $\begin{array}{l}\text { No. of } \\
\text { mutations }\end{array}$ \\
\hline Beta-cardiac myosin heavy chain & MYH7 & $14 \mathrm{q} 12$ & 76 \\
Myosin-binding protein C & MyBPC-3 & $11 \mathrm{p} 11.2$ & 33 \\
Troponin T & TnT2 & $1 \mathrm{q} 32$ & 15 \\
Troponin I & TnI3 & $19 \mathrm{q} 13.4$ & 8 \\
Alpha-tropomyosin & Tpm & $15 \mathrm{q} 22.1$ & 6 \\
Myosin essential light chain & MYl3 & 3p21.2-3p21.3 & 8 \\
Myosin regulatory light chain & MY12 & $12 \mathrm{q} 23-12 \mathrm{q} 24.3$ & 2 \\
Alpha-cardiac actin & ACTC & $15 \mathrm{q} 11-\mathrm{q} 14$ & 5 \\
Titin & TTN & 2q24.3 & 1 \\
\hline
\end{tabular}

Compiled from the FHC mutation database (http://www.angis.org.au/Databases/Heart/ heartbreak.html)

FHC, Familial hypertrophic cardiomyopathy

Table 2. Location of major mutations in the $M Y H 7$ gene

\begin{tabular}{lll}
\hline Exon & No. of mutations & Functional domain \\
\hline 9 & 5 & ATPase pocket \\
16 & 7 & Actin binding \\
19 & 6 & SH3 helix \\
20 & 8 & Converter \\
22 & 6 & Tail helix/rod \\
23 & 7 & Tail helix/rod \\
\hline
\end{tabular}

myosin-binding protein C. Thin filaments consist predominantly of actin and of lesser amounts of regulatory proteins, namely, tropomyosin and troponin. In the resting muscle, binding of tropomyosin to the active site of actin prevents cross-bridge formation between actin and myosin, thus preventing muscle contraction. The process of contraction is initiated by the release of calcium ions from the sarcoplasmic reticulum of the heart muscle cells. The calcium ions bind to troponin, causing the latter to move the tropomyosin molecule away from the cross-bridge binding sites of actin. Subsequently, adenosine triphosphate (ATP) molecules bound to myosin are hydrolyzed by adenosine triphosphatase (ATPase) to produce an energized myosin molecule and the cross-bridge of the energized myosin molecule binds to actin to trigger the release of the energy stored in the myosin head. Energy release corresponds to the movement of the bound cross-bridge in a rowing motion, bringing the actin molecules toward the center of the sarcomere. An ATP molecule binds to the myosin molecule and releases the cross-bridge attachment; the myosin is now ready to bind to another actin site, as long as calcium is present.

Recent advances in biochemistry and molecular genetics have allowed a better understanding of the molecular basis for FHC. By using linkage analysis and molecular genetic studies, nine disease genes for FHC have so far been identified. These include $\beta$-cardiac myosin heavy chain (MYH7) (Geisterfer-Lowrance et al. 1990; Watkins et al. 1992), cardiac myosin-binding protein C (MyBPC-3) (Watkins et al. 1995a), cardiac troponin T (TnT2) (Thierfelder et al. 1994), cardiac troponin I (TnI3) (Kimura et al. 1997), $\alpha$-tropomyosin (Tpm) (Watkins et al. 1995b), titin (TTN) (Satoh et al. 1999), $\alpha$-cardiac actin (ACTC) (Mogensen et al. 1999), and the essential and regulatory myosin light chains ( $M y l 3 /$ Myl2) (Poetter et al. 1996) (Table 1). Because all the mutations in FHC patients so far identified are present in the structural proteins of the muscle, the disease has been termed "a disease of the sarcomere" (Thierfelder et al. 1994).

FHC is inherited as an autosomal dominant trait. Thus, individuals with FHC must have one affected parent and frequently have multiple affected relatives. Sporadic occurrence is relatively rare. The variable clinical phenotypes of the disease can in part be explained by the underlying genetic heterogeneity. The genetic heterogeneity is accentuated by the fact that mutations in several exons of the sarcomere genes can cause FHC. To some extent, it has been possible to correlate different mutations with different prognoses and variable echocardiographic findings.

\section{$\beta$-Cardiac myosin heavy chain gene}

Myosin is the major contractile protein in the heart muscle and is responsible for force generation as a result of its pulling action on actin at the expense of ATP. The first mutation to be identified in FHC was a missense mutation in the $\beta$-cardiac myosin heavy chain gene (MYH7) (Tanigawa et al. 1990; Geisterfer-Lowrance et al. 1990). Several distinct missense mutations have since been identified in this gene that result in the substitution of conserved amino acids (Watkins et al. 1992; Vikstrom and Leinwand 1996). Because each of the affected amino acids is evolutionarily highly conserved, it has been suggested that these mutations may compromise normal functioning of the protein (Watkins et al. 1992). Several mutations are clustered in the globular head region, and may occur in regions that form functionally important domains (Table 2). A significant fraction of mutations detected so far fall in the tail-helix that lies in the rod region of the protein (Table 2). 
Recently, two families were shown to harbor mutations in the light meromyosin domain in the rod region of the protein (Blair et al. 2002). The MYH7 mutations account for about $30 \%$ of the reported FHC cases (Table 1) (Watkins et al. 1995c). To date more than 70 different mutations have been identified in the MYH7 gene (Table 1). Some are associated with sudden death (p.R403Q), but several also have a benign phenotype (p.V606M) (Epstein et al. 1992; Fananapazir and Epstein 1994).

\section{Characterization of specific MYH7 mutations}

Although a lot of research has gone into the characterization of several MYH7 gene mutations, including in vitro studies and animal models, we still know very little about the link between specific mutations, and hypertrophy and myocyte disarray. The most well characterized $M Y H 7$ mutation is $\mathrm{p} . \mathrm{R} 403 \mathrm{Q}$. This is primarily because it is associated with sudden death in most cases. Sweeny and coworkers (1994) demonstrated that the p.R403Q mutation resulted in an $80 \%$ reduction in the filament sliding speed in vitro, whereas Lankford and coworkers (1996) showed reduced power output in the muscle containing the mutated protein.

Rayment and colleagues (1995) analyzed the effect of 29 mutations in $M Y H 7$ that are implicated in FHC by using the crystal structure of the chicken skeletal myosin S1 peptide. They showed that most of the mutations were clustered around specific sites, viz, the actin-binding interface, the nucleotide-binding pocket, or the interface of the heavy chain with the essential light chain (ELC). Some of the mutations in the actin-binding interface could either affect the velocity of filament sliding, as seen in an in vitro motility assay, or lead to a reduced actin-activated Mg-ATPase activity (Cuda et al. 1993). The mutations in the nucleotidebinding pocket can compromise the catalytic function of the protein. Other mutations that lie in the binding site for the ELC show the importance of the interface between the ELC and the myosin heavy chain because this is required for coupling ATP hydrolysis with movement. However, as more and more mutations are being identified and characterized, it is becoming obvious that the mutations are actually spread throughout the gene.

Sata and Ikebe (1996) expressed and purified mutated forms of the cardiac myosin heavy chain and analyzed their motor and enzymatic properties in vitro. They specifically checked four mutant proteins, all of which showed decreased motor function in terms of ATPase activity and actin translocation. Interestingly, the degree of dysfunction in vitro correlated with the prognosis of the disease resulting from the mutation. The survival values for p.V606M (actin-myosin interface), p.R249Q (ATP pocket), p.R403Q (actin-myosin interface), and p.R453C (ATP pocket) were $94 \%, 79 \%, 36 \%$, and $34 \%$, respectively. This correlated with the extent of decrease in myosin motor activity. However, despite differences in prognosis, all mutations resulted in comparable levels of hypertrophy, indicating that other factors may influence cardiac hypertrophy resulting from this mutation. Roopnarine and Leinwand
(1998) analyzed the ATPase activities of three mutations (p.R249Q, p.R403Q, and p.V606M). The mutant proteins were expressed and purified and then assayed for their ATPase activities. The p.R249Q mutant (which falls in the base of the ATPase pocket) exhibited a 1.7-fold reduction in maximum Velocity (Vmax). A more severe affect was observed with the p.R403Q mutation (located at the base of a loop that appears to play an important role during the stereospecific actin-myosin interaction). The Vmax decreased 3.5-fold, suggesting that the actin-myosin interaction is weakened substantially. The Vmax of the p.V606M (present in the actin-binding domain) was affected to a lesser degree compared with the wild-type protein. Therefore, these results correlate with the moderate prognosis of the p.R249Q mutation, the poor prognosis of the p.R403Q mutation, and the good prognosis of the p.V606M mutation. A study on a Korean family revealed that the p.G716R mutation may be associated with sudden and early death (Tae-Hong et al. 1998). These results indicate that there may be a somewhat specific genotype-phenotype correlation for the different $M Y H 7$ mutations.

Geisterfer-Lowrance and coworkers (1996) developed a mouse model for the p.R403Q mutation and showed that the clinical features in the mice were similar to those observed in human patients. A transgenic rabbit model (harboring the p.R403Q mutation in the $M Y H 7$ gene) for human hypertrophic cardiomyopathy has also been developed (Marian et al. 1999). The symptoms, including premature death, were similar to those observed in human, thus showing that the rabbit could be a desirable model for studying FHC. The mouse model was also used to understand the basis for the highly malignant phenotype of the p.R403Q mutation (Tyska et al. 2000). The work of Tyska et al. (2000) revealed that the mutant protein actually exhibits a 2.3-fold higher actin-activated ATPase activity, a 2.2-fold greater average force generation, and a 1.6-fold faster actin filament sliding in the motility assay. Therefore, an abnormal power output rather than a compensatory response could lead to hypertrophic response in this mouse model.

Richard and coworkers (1999) showed the presence of double heterozygosity in a French Caribbean family suffering from FHC. They analyzed 15 subjects and reported the presence of a mutation in the $M Y H 7$ gene in exon 15 (p.E483K) in four subjects, a mutation in the $M y B P C 3$ gene in exon 30 (p.E1096 termination codon) in two subjects, and double heterozygosity in two subjects. As expected, the latter two subjects exhibited a significantly greater left ventricular hypertrophy than did the other affected subjects, although the double mutation was not lethal. Compound heterozygotes for the $M Y H 7$ gene resulting in FHC have also been described (Nishi et al. 1995; Jeschke et al. 1998). Most studies on FHC resulting from mutations in the MYH7 gene indicate that the mutated protein gets incorporated into the sarcomere and exerts a dominant negative effect, leading to a compensatory hypertrophic response. 
Cardiac myosin-binding protein $\mathrm{C}(M y B P C 3)$ gene

Cardiac myosin-binding protein $\mathrm{C}(\mathrm{MyBPC})$ is the predominant myosin-binding protein in the heart muscle and, unlike myosin, is not expressed in other tissues (Gautel et al. 1995). It is thought to participate in thick filament assembly by binding myosin and titin, thus probably contributing to sarcomere stability (Schultheiss et al. 1990). The protein also has regulatory activities (Moos and Feng 1990; Schlender and Bean 1991). Unlike $M Y H 7$, mutations in the $M y B P C 3$ appear to be in general associated with significant hypertrophy but with good prognosis. The phenotypic expression of mutations occurs late in the life of affected individuals, the reasons for which are not yet clear.

The mutations identified in $M y B P C 3$ are mostly splice site mutations and, to a lesser extent, exon duplications (Bonne et al. 1995; Watkins et al. 1995a). In a majority of the cases, the mutation results in the formation of a truncated protein, which may lose the ability to bind to the myosin heavy chain (Bonne et al. 1995; Freiburg and Gautel 1996; Okagi et al. 1993). A few missense mutations have also been identified in this gene, including a study on a South-African family (Moolman-Smook et al. 1998). Yu and his colleagues (1998) analyzed two different mutations in two Australian families. One mutation (generation of a premature stop codon instead of glutamine at position 969) resulted in a truncated protein (devoid of the C-terminal 75 amino acids), which was unable to bind to cardiac myosin, and led to an accumulation of disorganized myofibrils resulting in a compensatory hypertrophic response. The second mutation (p.N755K) was a missense mutation located in a highly conserved region of the protein (linker region between the phosphorylation site and the myosin/titin binding region), which resulted in alteration of the function of the protein, leading to cardiac hypertrophy.

Animal models have been used to determine the development and progression of disease resulting from mutations in the $M y B P C 3$ gene. Transgenic mice expressing mutant forms of the protein exhibited a decreased shortening velocity and power output and significant changes in the ultrastructure of the heart (Yang et al. 1998, 1999). The results also showed that the mutant protein behaved as a poison polypeptide (Yang et al. 1999). The mouse model of a homozygous mutant $M y B P C 3$ gene was shown to result in dilated cardiomyopathy (McConnell et al. 1999). A knock-in mouse model of the N-terminal deleted gene was created recently (Witt et al. 2001). The left ventricular muscle fibers in the transgenic mice exhibited an increased sensitivity to $\mathrm{Ca}^{2+}$, whereas overall force production was not altered (Witt et al. 2001). This provides a clue as to why the N-terminal mutant proteins lead to a hypercontractile state of the affected muscle fibers.

\section{Troponin $\mathrm{T}$ gene}

The function of troponin is to move the tropomyosin away, resulting in exposure of the myosin-binding sites on actin. Missense mutations as well as splice site mutations have been identified in the troponin $\mathrm{T}$ gene (TnT2; Thierfelder et al. 1994; Watkins et al. 1995b). Unlike MYH7 and $M y B P C 3$, mutations in TnT2 appear to be largely associated with normal ventricular thickness or mild hypertrophy but with a significantly greater frequency of sudden death (Watkins et al. 1995b). A missense mutation (p.R92Q) was tested by Oberst and colleagues (1998) in a transgenic mouse model, and the results once again showed that hypertrophic cardiomyopathy was caused by a dominantnegative effect exerted by the mutant peptide. Watkins and coworkers (1996) studied the IVS15G $>$ A splice site mutation that inactivates a $5^{\prime}$ splice donor site, leading to either skipping of exon 15 or activation of a cryptic splice site. Both aberrant cDNAs encode a truncated TnT2 peptide lacking the conserved $\mathrm{C}$ terminus. The analysis of Watkins et al. (1996) revealed that the truncated protein was incorporated into the sarcomere. However, the force generated was less than the sarcomere containing the wildtype full-length TnT2 peptide, indicating that the truncated peptide exerted a dominant-negative effect.

Surprisingly, the study of the p.I91N mutation in rat TnT2 (Lin et al. 1996) showed that the mutated protein exhibited a $50 \%$ faster thin filament movement rate. This result is similar to the one obtained by Tyska and coworkers (2000) for the MYH7 p.R403Q mutation. Another study involving incorporation of mutant proteins in rabbit cardiac myofibrils indicated increased contractility of the cardiac muscle owing either to $\mathrm{Ca}^{2+}$ sensitization or potentiation of the maximum level of ATPase activity (Yanaga et al. 1999). Sweeney and coworkers (1998) suggested an alternative mechanism for the disease (distinct from the dominantnegative mechanism). Their work on two mutations, viz., p.I91N and p.R92Q, revealed that these mutations might lead to an increase in the cost of force production (less force generated per ATP molecule). However, the total reduction in the force generation may be minimal, thus explaining the moderate to nil hypertrophy seen in patients having mutations in $T n T 2$. Thus, even in the absence of hypertrophy, increased cardiac output could result in energy demands that cannot be met, leading to arrhythmias and sudden death. Montgomery and coworkers (2001) have shown that the extent of mutation-induced dysfunction depends not only on the nature of the TnT2 mutation, but also on the concentration of the mutant protein in the sarcomere. A study of the p.S179F mutation in exon 11 revealed that it results in sudden death in affected individuals when present in a homozygous state (Ho et al. 2000). Sehnert and colleagues (2002) made an important observation regarding the coexpression of different thin-filament constituents. By using the zebra fish model, they showed that TnT2 null mutants resulted in a significant reduction in levels of alpha tropomyosin and troponin I (Sehnert et al. 2002). The p.R141W TnT2 mutant has been shown to cause dilated cardiomyopathy ( $\mathrm{Li}$ et al. 2001). Interestingly, it has been shown that the altered thin-filament regulation caused by mutant TnT2, which causes dilated cardiomyopathy, is different from that caused by mutants that result in hypertrophic cardiomyopathy (Robinson et al. 2002). Recently, an interesting observation of coexistence of Friedreich's ataxia triplet repeat expansion and cardiac troponin $\mathrm{T}$ 
mutation has been reported in a 5-year-old boy (Cuda et al. 2002).

\section{Troponin I (TnI3) gene}

The TnI3 is the inhibitory subunit of the troponin complex. The inhibition is released when calcium binds to the troponin C subunit. Several mutations leading to FHC have been identified in this gene, the majority of which are missense mutations. Three mutations lie in the inhibitory region, whereas the rest are located in the $\mathrm{C}$-terminal region. Some of these mutations may result in apical hypertrophy (Kimura et al. 1997). One of them, viz., p.R145G, was studied in a mouse model. The results showed cardiomyocyte disarray, interstitial fibrosis, and premature death (James et al. 2000). The functional alterations that seemed to be responsible for the development of cardiac disease included increased skinned fiber sensitivity to calcium and, at the whole organ level, hypercontractility with diastolic dysfunction (James et al. 2000). It has been shown that the p.R145G and p.R162W mutations of the TnI gene, which have been associated with FHC, may cause the disease via impaired relaxation rather than impaired contraction, as seen with some other classes of mutants (Elliott et al. 2000).

Takahashi-Yanaga and colleagues (2001) studied the effect of several TnI3 mutations. Their results demonstrated that most of the FHC-linked cTnI mutations did affect the regulatory processes involving the TnI3 molecule, and that at least five mutations (p.R145G, p.R145Q, p.R162W, K183del, and p.K206Q) increased the $\mathrm{Ca}^{2+}$ sensitivity of cardiac muscle contraction (Takahashi-Yanaga et al. 2001). The R145G mutation has been shown to result in severe diastolic dysfunction and somewhat decreased contractility leading to hypertrophy as a compensatory mechanism (Lang et al. 2002). The K183del is the most common mutation found in this gene. Kokado and colleagues (2000) showed in a study of 25 individuals from seven families that this mutation resulted in variable clinical presentation (Kokado et al. 2000), once again pointing to the role of other factors in the prognosis of the disease. Recently, the lysine 183 deletion was shown to lead to septal wall thinning and systolic dysfunction (Shimizu et al. 2002). Studies on this mutation have also shown generation of abnormal Q waves in patients, which could be an indication for sudden cardiac death (Shimizu et al. 2002). Burton and coworkers (2002) have shown that two mutations, viz., p.R145G and p.G203S, exhibited different effects on motility and ATPase activity. They set up in vitro assays using recombinant mutant proteins expressed in Escherichia coli that revealed that the p.G203S mutant exhibited reduced inhibition in the motility assay. However, the action of p.R145G was indistinguishable from that of the wild-type protein, indicating that this mutant protein led to hypertrophic cardiomyopathy without affecting its function in force production.

\section{$\alpha$-Tropomyosin (Tpm) gene}

The function of tropomyosin is to cover the myosin-binding sites on actin. Exon 5 and exon 2 of the gene are involved in a majority of the missense mutations. A study of about 60 Japanese families revealed that the clinical phenotypes of different mutants are similar, reflecting a common mechanism by which dysfunctional thin filaments trigger cellular hypertrophy (Yamauchi-Takihara et al. 1996). Investigators showed that four different $\alpha$-tropomyosin mutants resulted in an inappropriate increased force output at submaximal levels of calcium. Michele and coworkers (1999) have shown that the severity of a direct calcium-sensitizing effect of mutations in $\alpha$-tropomyosin correlated with the extent of severity of FHC (Michele et al. 1999). Recently, Prabhakar and colleagues (2001) studied a mouse model for the Q180G mutation that exhibited a very severe phenotype of the disease. A novel deletion mutation in the $\alpha$ tropomyosin gene has been identified in a Japanese patient with hypertrophic cardiomyopathy (Nakajima-Taniguchi et al. 1995). Some mutant forms of $\alpha$-tropomyosin may also result in dilated cardiomyopathy (Olson et al. 2001).

Essential and regulatory myosin light chain genes $(M y l 3 / M y l 2)$

Poetter and colleagues (1996) hypothesized that, because mutations in the ELC-binding region of the myosin heavy chain have been implicated in FHC, it was possible that mutations in the ELC itself could also trigger FHC. Therefore, they amplified the seven exons of the human cardiac/ skeletal ELC gene separately and showed the presence of a mutation (p.M149V) in 1 of the 383 families screened. They showed that the rate of actin translocation in myosin isolated from these patients was higher compared with normal. Similar results were obtained when a mutated myosin heavy chain (p.R719Q), which lies adjacent to the ELC mutation, was used in the assay. The cardiac phenotype in these patients was a rare subtype of FHC, which involved massive hypertrophy of the cardiac papillary muscles, causing a midcavity obstruction. They also screened 399 unrelated FHC cases for mutations in the adjacent myosin regulatory light chain (RLC) and found three independent mutations (p.A3T, p.E22K, p.P94R). The cardiac morphology in these patients was strikingly similar to the patients with mutations in the ELC gene. These studies show that mutation in those regions of ELC and RLC that may be involved in binding to the myosin heavy chain may lead to FHC.

\section{$\alpha$-Cardiac actin $(A C T C)$ gene}

Actin is the major constituent of thin filaments and is directly involved in force generation. Mogensen and coworkers (1999) have identified $\alpha$-cardiac actin as a novel disease gene for FHC. The gene has a p.A295S mutation in exon 5, which results in impaired myosin binding by the protein, leading to impaired force generation and, hence, compensatory hypertrophy. Mutations in this gene can also cause inherited idiopathic dilated cardiomyopathy (IDC) (Takai et al. 1999). Mogensen and coworkers (1999) have shown in their study that mutations affecting sarcomere contraction 
led to FHC, whereas mutations affecting force transmission from the sarcomere to the surrounding syncytium led to IDC.

\section{Titin}

The titin gene is perhaps the second-largest human gene known to date and is an important component of the cardiac sarcomere. Satoh and coworkers (1999) identified titin as a candidate FHC gene based on analysis of $82 \mathrm{FHC}$ patients who did not harbor mutation in any of the other known genes. The p.R740L mutation resulted in an increase in the binding affinity of titin for alpha-actin in the yeast two-hybrid system. These observations suggest that the titin mutation may cause hypertrophic cardiomyopathy in this patient via altered affinity to alpha-actin.

\section{Evidence for involvement of multiple factors}

Although FHC is predominantly recognized as a unigene disorder, the overall clinical symptoms may be modulated by other factors distinct from the sarcomeric mutations. In other words, patients with identical mutations may sometimes have different clinical features, indicating factors such as modifier genes, sex, physical activity, nutrition, ethnic background, and other environmental factors may affect the phenotypic expression of FHC. The most obvious factor is the extent of physical activity in the patient (Maron et al. 1998). In a few cases, the disease has been observed to have a somewhat sex-specific phenotype, resulting from a variation in the development of hypertrophy and progression to heart failure. However, there does not appear to be a contrasting difference between the two sexes. Our studies on one Indian family, which harbors a mutation in the 22nd exon of the MYH7 gene, revealed clinical heterogeneity among various affected members of the same family (M.D. Bashyam et al. 2002, unpublished observations). Several studies have revealed the involvement of other genetic loci in the prognosis of FHC. The most important among these appear to be the genes that constitute the renin-angiotensin system. The angiotensin-converting enzyme gene $(A C E)$ has been shown specifically to affect the prognosis in some cases (Lechin et al. 1995; Marian et al. 1993). This issue has also been addressed by Ortlepp and coworkers (2002), who showed that penetrance of a myosinbinding protein $\mathrm{C}$ mutation was dependent on a genetic polymorphism associated with the renin-angiotensin system. The DD allele of the ACE I gene has been shown to be associated with a severe form of hypertrophy and sudden death in patients with FHC (Marian et al. 1993; Iwai et al. 1994). It is possible that the extent of the contribution of this allele may be different in different mutations. Tesson and colleagues (1997) established an association of the Ace I D allele with the $M Y H 7$ p.R403Q mutation, but not with the $M y B P C 3$ mutations, raising the possibility of a role for additional genetic modifiers. Recently, Semsarian and coworkers (2001) used a mouse model to address the question of other genetic markers that may influence phenotypic expression of the disease.

\section{Interesting posers}

The wide spectrum of genetic heterogeneity makes it essential to use a high-throughput screening technology for mutation detection. Recently, microarray technology was adapted for this purpose with good results (Waldmuller et al. 2002). As mentioned earlier, the clinical diversity of the disease can in some cases be explained by the underlying genetic heterogeneity. However, it is difficult at this time to state with any degree of certainty that a particular mutation will result in a specific phenotype. However, some definite patterns have emerged over the past few years pertaining to mutations in the $M Y H 7, T n T 2$, and $M y B P C 3$ genes, probably because mutations in these genes are more common and consequently more research has been carried out on them. For $M Y H 7$, the prognosis appears to be different for different mutations. For example, the p.R403Q mutation is usually associated with a severe phenotype, leading to sudden death in most cases, whereas the p.V606M mutation is usually more benign. Most mutations in the TnT2 gene are associated with low penetrance and subclinical hypertrophy but a very high incidence of sudden death. Mutations in the $M y B P C 3$ gene are usually associated with a better prognosis and a delayed onset of symptoms. Recently, Niimura and colleagues (2002) showed that hypertrophic cardiomyopathy in the elderly was caused mainly by mutations in the cardiac myosin-binding protein $\mathrm{C}$, troponin $\mathrm{I}$, or the alphacardiac myosin heavy chain genes, and was not due to genes such as beta-cardiac myosin heavy chain, troponin $\mathrm{T}$, and alpha tropomyosin.

There are several interesting aspects of the disease that are worth investigating. For example, the molecular basis for the hypertrophic response is not clear. The link between the mutations and different kinds of hypertrophic response also remains to be elucidated. Numerous studies indicate that $\mathrm{Ca}^{2+}$ could be a primary signal for cardiac hypertrophy, not only because the release of calcium is the primary step in muscle contraction, but also because hypertrophic agonists are known to activate calcium-dependent signaling. It has been shown that a calcium-regulated transcription factor, nuclear factor of activated T cells (NFAT) interacts with the cardiac-specific transcription factor involved in the hypertrophic response, viz., GATA4. This suggests a possible link between hypertrophy and regulation of calcium levels (Reddy 1997). Experimental induction of cardiac hypertrophy (such as by using mechanical stress) has been shown to induce intracellular signaling pathways involving the Ras-dependent mitogen-activated protein kinase cascade (Sadoshima and Izumo 1993). The role of c$\mathrm{H}$-ras and c-myc in the hypertrophic response has also been studied. c-H-ras expression is normal throughout cardiac development and after birth (Komuro et al. 1988), whereas c-myc is expressed only during embryonic stages and is undetectable after birth (Simpson 1988). Recent studies 
have indicated that $\mathrm{c}-\mathrm{H}$-ras expression is up-regulated during hypertrophy, and c-myc-positive patients show greater myocyte hypertrophy than do c-myc-negative patients (Kai et al. 1998). Therefore, the induction of these two genes may be an important step leading to hypertrophy. Calciumcalmodulin activated phosphatase-Calcineurin has been implicated in playing a major role in cardiac hypertrophy (Wilkins and Molkentin 2002). Several other growth factors, such as c-fos, c-jun, atrial and brain natriuretic peptides, and endothelin I, have been shown to be possibly involved in not only pressure overload hypertrophy but also in hypertrophy resulting from sarcomere gene mutations (Kai et al. 1998; Derchi et al. 1992; Hasegawa et al. 1993, 1996). Adult cardiomyocytes in FHC have been shown to reactivate fetal isoforms and to down-regulate adult forms of several cardiac genes, including the cardiac myosin heavy chain gene (Komuro et al. 1988; Chien et al. 1993). However, the cascade of events leading to this switch is yet to be determined.

Given the underlying genetic heterogeneity, it is possible that other disease genes for FHC may be identified in the future. This may actually further complicate attempts to establish a genotype-phenotype correlation. Therefore, it is important to include clinical data for each mutation identified so far in existing FHC mutation databases to facilitate such a correlation. A study of FHC in relation to its epidemiology and nongenetic factors may give a clue as to the etiology and help in better prognosis and preclinical and presymptomatic diagnosis.

\section{References}

Blair E, Redwood C, de Jesus Oliveira M, Moolman-Smook JC, Brink P, Corfield VA, Ostman-Smith I, Watkins H (2002) Mutations of the light meromyosin domain of the beta-myosin heavy chain rod in hypertrophic cardiomyopathy. Circ Res 90:263-269

Bonne G, Carrier L, Bercovici J, Cruaud C, Richard P, Hainque B, Gautel M, Labeit S, James M, Beckmann J (1995) Cardiac myosin binding protein-C gene splice acceptor site mutation is associated with familial hypertrophic cardiomyopathy. Nat Genet 11:438-440

Burton D, Abdulrazzak H, Knott A, Elliott K, Redwood C, Watkins H, Marston S, Ashley C (2002) Two mutations in troponin I that cause hypertrophic cardiomyopathy have contrasting effects on cardiac muscle contractility. Biochem J 362:443-451

Chien KR, Zhu H, Knowlton KU, Miller-Hance W, van-Bilsen M, O'Brien TX, Evans SM (1993) Transcriptional regulation during cardiac growth and development. Annu Rev Physiol 55:77-95

Cuda G, Fananapazir L, Zhu WS, Sellers JR, Epstein ND (1993) Skeletal muscle expression and abnormal function of beta-myosin in hypertrophic cardiomyopathy. J Clin Invest 91:2861-2865

Cuda G, Mussari A, Concolino D, Costanzo FS, Strisciuglio P (2002) Co-existence of frataxin and cardiac troponin $\mathrm{T}$ gene mutations in a child with Friedreich Ataxia and familial hypertrophic cardiomyopathy. Hum Mutat 19:309-310

Davies MJ (1984) The current status of myocardial disarray in hyptertrophic cardiomyopathy. Br Heart J 51:361-366

Derchi G, Bellone P, Chiarella F, Randazzo M, Zino V, Vecchio C (1992) Plasma levels of atrial natriuretic peptide in hypertrophic cardiomyopathy. Am J Cardiol 70:1502-1504

Elliott K, Watkins H, Redwood CS (2000) Altered regulatory properties of human cardiac troponin I mutants that cause hypertrophic cardiomyopathy. J Biol Chem 275:22069-22074

Epstein ND, Cohn GM, Cyran F, Fananapazir L (1992) Differences in clinical expression of hypertrophic cardiomyopathy associated with two distinct mutations in the beta-myosin heavy chain gene. A 908LeuVal mutation and a 403ArgGln mutation. Circulation 86:345352

Fananapazir L, Epstein ND (1994) Genotype-phenotype correlation in hypertrophic cardiomyopathy. Insights provided by comparisons of kindreds with distinct and identical beta-myosin heavy chain gene mutations. Circulation 89:22-32

Freiburg A, Gautel M (1996) A molecular map of the interactions between titin and myosin-binding protein-C. Implications for sarcomeric assembly in familial hypertrophic cardiomyopathy. Eur J Biochem 235:317-323

Gautel M, Zuffardi O, Freiburg A, Labeit S (1995) Phosphorylation switches specific for the cardiac isoform of myosin binding protein-C: a modulator of cardiac contraction? EMBO J 14:1952-1960

Geisterfer-Lowrance A, Kass S, Tanigawa G (1990) A molecular basis for familial hypertrophic cardiomyopathy: a beta cardiac myosin heavy chain gene missense mutation. Cell 62:999-1006

Geisterfer-Lowrance AA, Christe M, Conner DA, Ingwall JS, Schoen FJ, Seidman CE, Seidman JG (1996) A mouse model of familial hypertrophic cardiomyopathy. Science 272:731-734

Grossman W, Jones D, McLaurin LP (1975) Wall stress and patterns of hypertrophy in the human left ventricle. J Clin Invest 56:56-64

Hasegawa K, Fujiwara H, Doyama K, Mukoyama M, Nakao K, Fujiwara T, Imura H, Kawai C (1993) Ventriclar expression of brain natriuretic peptide in hypertrophic cardiomyopathy. Circulation 88:372-380

Hasegawa K, Fujiwara H, Koshiji M, Inada T, Ohtani S, Doyama K, Tanaka M, Matsumori A, Fujiwara T, Shirakami G, Hosoda K, Nakao K, Sasayama S (1996) Endothelin-I and its receptor in hypertrophic cardiomyopathy. Hypertension 27:259-264

Ho CY, Lever HM, DeSanctis R, Farver CF, Seidman JG, Seidman CE (2000) Homozygous mutation in cardiac troponin T: implications for hypertrophic cardiomyopathy. Circulation 102:1950-1955

Iwai N, Ohmichi N, Nakamura Y, Kinoshita M (1994) DD genotype of the angiotensin-converting enzyme gene is a risk factor for left ventricular hypertrophy. Circulation 90:2622-2628

James J, Zhang Y, Osinska H, Sanbe A, Klevitsky R, Hewett TE, Robbins J (2000) Transgenic modeling of a cardiac troponin I mutation linked to familial hypertrophic cardiomyopathy. Circ Res 87:805-811

Jeschke B, Uhl K, Weist B, Schroder D, Meitinger T, Dohlemann C, Vosberg HP (1998) A high risk phenotype of hypertrophic cardiomyopathy associated with a compound genotype of two mutated $\beta$-myosin heavy chain genes. Hum Genet 102:299-304

Kai H, Muraishi A, Sugiu Y, Nishi H, Seki Y, Kuwahara F, Kimura A, Kato H, Imaizumi T (1998) Expression of proto-oncogenes and gene mutation of sarcomeric proteins in patients with hypertrophic cardiomyopathy. Circ Res 83:594-601

Kimura A, Harada H, Park JE, Nishi H, Satoh M, Takahashi M, Hiroi S, Sasaoka T, Ohbuchi N, Nakamura T, Koyanagi T, Hwang TH, Choo JA, Chung KS, Hasegawa A, Nagai R, Okazaki O, Nakamura H, Matsuzaki M, Sakamoto T, Toshima H, Koga Y, Imaizumi T, Sasazuki T (1997) Mutations in the cardiac troponin I gene associated with hypertrophic cardiomyopathy. Nat Genet 16:379-382

Kokado H, Shimizu M, Yoshio H, Ino H, Okeie K, Emoto Y, Matsuyama T, Yamaguchi M, Yasuda T, Fujino N, Ito H, Mabuchi H (2000) Clinical features of hypertrophic cardiomyopathy caused by a Lys 183 deletion mutation in the cardiac troponin I gene. Circulation 102:6636-6639

Komuro I, Kurabayashi M, Takaku F, Yazaki Y (1988) Expression of cellular oncogenes in the myocardium during the developmental stage and pressure-overloaded hypertrophy of the rat heart. Circ Res 62:1075-1079

Lang R, Gomes AV, Zhao J, Housmans PR, Miller T, Potter JD (2002) Functional analysis of a troponin I (R145G) mutation associated with familial hypertrophic cardiomyopathy. J Biol Chem 277:1167011678

Lankford EB, Epstein ND, Fananapazir L, Sweeney HL (1996) Abnormal contractile properties of muscle fibers expressing beta-myosin heavy chain gene mutations in patients with hypertrophic cardiomyopathy. J Clin Invest 95:1409-1414

Lechin M, Quinones MA, Omran A, Hill R, Yu QT, Rakowski H, Wigle D, Liew CC, Sole M, Roberts R, Marian AJ (1995) Angiotensin-I converting enzyme genotypes and left ventricular hypertrophy in patients with hypertrophic cardiomyopathy. Circulation 92:1808-1812 
Li D, Czernuszewicz GZ, Gonzalez O, Tapscott T, Karibe A, Durand JB, Brugada R, Hill R, Gregoritch JM, Anderson JL, Quinones M, Bachinski LL, Roberts R (2001) Novel cardiac troponin T mutation as a cause of familial dilated cardiomyopathy. Circulation 104:21882193

Lin D, Bobkova A, Homsher E, Tobachman L (1996) Altered cardiac troponin $\mathrm{T}$ in vitro function in the presence of a mutation implication in familial hypertrophic cardiomyopathy. J Clin Invest 97:2842-2848

Marian AJ, Yu QT, Workman R, Greve G, Roberts R (1993) Angiotensin-converting enzyme polymorphism in hypertrophic cardiomyopathy and sudden cardiac death. Lancet 342:1085-1086

Marian AJ, Wu YU, Lim DS, McCluggage M, Youker K, Yu QT, Brugada R, DeMayo F, Quinones M, Roberts R (1999) A transgenic rabbit model for human hypertrophic cardiomyopathy. J Clin Invest 104:1683-1692

Maron BJ, Roberts WC, Edwards JE, McAllister HA, Foley DD, Epstein SE (1978) Sudden death in patients with hypertrophic cardiomyopathy. Characterization of 26 patients without functional limitation. Am J Cardiol 41:803-810

Maron BJ, Roberts WC, Epstein S (1986) Causes of sudden death in competitive athletes. J Am Coll Cardiol 7:204-214

Maron BJ, Bonow RO, Cannon RO, Leon MB, Epstein SE (1987) Hypertrophic cardiomyopathy: interrelations of clinical manifestation, pathophysiology and therapy. N Engl J Med 316:780-789

Maron BJ, Mitten MJ, Quandt EF, Zipes DP (1998) Competitive athletes with cardiovascular disease: the case of Nicholas Knapp. N Engl J Med 339:1632-1635

McConnell BK, Jones KA, Fatkin D, Arroyo LH, Lee RT, Aristizabal $\mathrm{O}$, Turnbull DH, Gergakopoulos D, Kass D, Bond M, Niimura $\mathrm{H}$ Schoen FJ, Conner D, Fischman DA, Seidman CE, Seidman JG, Fischman DH (1999) Dilated cardiomyopathy in homozygous myosin-binding protein-C mutant mice. J Clin Invest 104:1235-1244

Michele DE, Albayya FP, Metzger JM (1999) Direct, convergent hypersensitivity of calcium-activated force generation produced by hypertrophic cardiomyopathy mutant $\alpha$-tropomyosins in adult cardiac myocytes. Nat Med 5:1413-1417

Mogensen J, Klausen IC, Pedersen AK, Egeblad H, Bross P, Kruse TA, Gregersen N, Hansen PS, Baandrup U, Borglum AD (1999) $\alpha$-cardiac actin is a novel disease gene in familial hypertrophic cardiomyopathy. J Clin Invest 103:R39-R43

Montgomery DE, Tardiff JC, Chandra M (2001) Cardiac troponin T mutations: correlation between the type of mutation and the nature of myofilament dysfunction in transgenic mice. J Physiol 15:583-592

Moolman-Smook JC, Mayosi B, Brink P, Corfield VA (1998) Identification of a new missense mutation in MyBP-C associated with hypertrophic cardiomyopathy. J Med Genet 35:253-254

Moos C, Feng IM (1990) Effect of C-protein on actomyosin ATPase. Biochim Biophys Acta 632:141-149

Nakajima-Taniguchi C, Matsui H, Nagata S, Kishimoto T, YamauchiTakihara K (1995) Novel missense mutation in alpha-tropomyosin gene found in Japanese patients with hypertrophic cardiomyopathy. J Mol Cell Cardiol 27:2053-2058

Niimura H, Patton KK, McKenna WJ, Soults J, Maron BJ, Seidman JG, Seidman CE (2002) Sarcomere protein gene mutations in hypertrophic cardiomyopathy of the elderly. Circulation 105:446-451

Nishi H, Kimura A, Harada H, Harada H, Imaizumi T, Toshima H, Sasazuki T, Kimura A (1995) A myosin missense mutation, not a nul allele, causes familial hypertrophic cardiomyopathy. Circulation 91:2911-2915

Oberst L, Ahao G, Park JT, Brugada R, Michael LH, Entman ML, Roberts R, Marian AJ (1998) Dominant-negative effect of a mutant cardiac troponin $\mathrm{T}$ on cardiac structure and function in transgenic mice. J Clin Invest 102:1498-1505

Okagi T, Weber E, Fischman DA, Vaughan KT, Mikawas T, Reinach FC (1993) The major myosin-binding domain of skeletal muscle MyBP-C (C protein) resides in the $\mathrm{COOH}$-terminal, immunoglobulin C2 motif. J Cell Biol 123:619-626

Olson TM, Kishimoto NY, Whitby FG, Michels VV (2001) Mutations that alter the surface charge of alpha-tropomyosin are associated with dilated cardiomyopathy. J Mol Cell Cardiol 33:723-732

Ortlepp JR, Vosberg HP, Reith S, Ohme F, Mahon NG, Schroder D, Klues HG, Hanrath P, McKenna WJ (2002) Genetic polymorphisms in the renin-angiotensin-aldosterone system associated with expression of left ventricular hypertrophy in hypertrophic cardiomyopathy: a study of five polymorphic genes in a family with a disease causing mutation in the myosin binding protein $\mathrm{C}$ gene. Heart 87:270-275
Poetter K, Jiang H, Hassanzadeh S, Master SR, Chang A, Dalakas MC, Rayment I, Sellers JR, Fananapazir L, Epstein ND (1996) Mutations in either the essential or regulatory light chains of myosin are associated with a rare myopathy in human heart and skeletal muscle. Nat Genet 13:63-69

Prabhakar R, Boivin GP, Grupp IL, Hoit B, Arteaga G, Solaro JR, Wieczorek DF (2001) A familial hypertrophic cardiomyopathy alpha-tropomyosin mutation causes severe cardiac hypertrophy and death in mice. J Mol Cell Cardiol 33:1815-1828

Rayment I, Holden HM, Sellers JR, Fananapazir L, Epstein ND (1995) Structural interpretation of the mutations in $\beta$-cardiac myosin that have been implicated in familial hypertrophic cardiomyopathy. Proc Natl Acad Sci USA 92:3864-3868

Reddy DS (1997) Cellular and molecular biology of cardiac hypertrophy. Curr Science 72:13-30

Richard P, Isnard R, Carrier L, Dubourg O, Donatien Y, Mathieu B, Bonne G, Gary F, Charron P, Hagege M, Komajda M, Schwartz K, Hainque B (1999) Double heterozygosity for mutations in the $\beta$ myosin heavy chain and in the cardiac myosin binding protein $\mathrm{C}$ genes in a family with hypertrophic cardiomyopathy. J Med Genet 36:542-545

Robinson P, Mirza M, Knott A, Abdulrassak H, Willott R, Marston S, Watkins H, Redwood C (2002) Alterations in thin filament regulation induced by a human cardiac troponin $\mathrm{T}$ mutant that causes dilated cardiomyopathy are distinct from those induced by troponin $\mathrm{T}$ mutants that cause hypertrophic cardiomyopathy. J Biol Chem 277:40710-40716

Roopnarine O, Leinwand LA (1998) Functional analysis of myosin mutations that cause familial hypertrophic cardiomyopathy. Biophys J 75:3023-3030

Sadoshima J, Izumo S (1993) Mechanical stretch rapidly activates multiple signal transduction pathways in cardiac myocytes: potential involvement of an autocrine/paracrine mechanism. EMBO J 12:1681-1692

Sata M, Ikebe M (1996) Functional analysis of the mutations in the human cardiac beta-myosin that are responsible for familial hypertrophic cardiomyopathy. Implication for the clinical outcome. J Clin Invest 98:2866-2873

Satoh M, Takahashi M, Sakamoto T, Hirle M, Marumo F, Kimura A (1999) Structural analysis of the titin gene in HCM: identification of a novel disease gene. Biochem Biophys Res Commun 262:411417

Schlender KK, Bean LJ (1991) Phosphorylation of chick cardiac Cprotein by calcium/calmodulin-dependent protein kinase II. J Biol Chem 266:2811-2817

Schultheiss T, Lin ZX, Lu MH, Murray J, Fischman DA, Weber K, Masaki T, Imamura M, Holtzer H (1990) Differential distribution of subsets of myofibrillar proteins in cardiac nonstriated and striated myofibril. J Cell Biol 110:1159-1172

Sehnert AJ, Huq A, Weinstein BM, Walker C, Fishman M, Stainier DY (2002) Cardiac troponin $\mathrm{T}$ is essential in sarcomere assembly and cardiac contractility. Nat Genet 31:106-110

Semsarian C, Healey MJ, Fatkin D, Giewat M, Duffy C, Seidman CE, Seidman JG (2001) A polymorphic modifier gene alters the hypertrophic response in a murine model of familial hypertrophic cardiomyopathy. J Mol Cell Cardiol 33:2055-2060

Shimizu M, Ino H, Okeie K, Yamaguchi M, Nagata M, Hayashi K, Itoh H, Iwaki T, Oe K, Konno T, Mabuchi H (2002) Septal wall thinning and systolic dysfunction in patients with hypertrophic cardiomyopathy caused by a cardiac troponin I gene mutation. Am Heart $\mathrm{J}$ 143:690-695

Simpson PC (1988) Role of proto-oncogenes in myocardial hypertrophy. Am J Cardiol 62:13G-19G

Sweeney HL, Straceski AJ, Leinwand LA, Tikunov BA, Faust L (1994) Heterologous expression of a cardiomyopathic myosin that is defective in its actin interaction. J Biol Chem 269:16031605

Sweeney HL, Feng HS, Yang Z, Watkins H (1998) Functional analyses of troponin $\mathrm{T}$ mutations that cause hypertrophic cardiomyopathy: insights into disease pathogenesis and troponin function. Proc Natl Acad Sci USA 95:14406-14410

Tae-Hong H, Lee W-H, Kimura A, Satoh M, Nakamura T, Kim MK, Choi SK, Park JE (1998) Early expression of a malignant phenotype of familial hypertrophic cardiomyopathy associated with a Gly716Arg myosin heavy chain mutation in a Korean family. Am J Cardiol 82:1509-1513 
Takahashi-Yanaga F, Morimoto S, Harada K, Minakami R, Shiraishi F, Ohta M, Lu QW, Sasaguri T, Ohtsuki I (2001) Functional consequences of the mutations in human cardiac troponin I gene found in familial hypertrophic cardiomyopathy. J Mol Cell Cardiol 33:20952107

Takai E, Akita H, Shiga N, Kanazawa K, Yamada S, Terachima M, Matsuda Y, Iwai C, Kawai K, Tokota Y, Yomoyama M (1999) Mutational analysis of the cardiac actin gene in familial and sporadic dilated cardiomyopathy. Am J Med Genet 86:325-327

Tanigawa G, Jarcho JA, Kass S, Solomon SD, Vosberg HP, Seidman JG, Seidman CE (1990) A molecular basis for familial hypertrophic cardiomyopathy: an alpha/beta cardiac myosin heavy chain hybrid gene. Cell 62:991-998

Tesson F, Dufour C, Moolman JC (1997) The influence of the angiotensin I converting enzyme genotype in familial hypertrophic cardiomyopathy varies with the disease gene mutation. J Mol Cell Cardiol 29:831-838

Thierfelder L, Watkins H, MacRae C, Lamas R, McKenna W, Vosberg HP, Seidman JG, Seidman CE (1994) Alpha-tropomyosin and cardiac troponin $\mathrm{T}$ mutations cause familial hypertrophic cardiomyopathy: a disease of the sarcomere. Cell 77:701-712

Tyska MJ, Hayes E, Giewat M, Seidman CE, Seidman JG, Warshaw DM (2000) Single-molecule mechanics of R403Q cardiac myosin isolated from the mouse model of familial hypertrophic cardiomyopathy. Circ Res 86:737-744

Vikstrom KL, Leinwand LA (1996) Contractile protein mutations and heart disease. Curr Opinion Cell Biol 8:97-105

Waldmuller S, Freund P, Mauch S, Toder R, Vosberg HP (2002) Lowdensity DNA microarrays are versatile tools to screen for known mutations in hypertrophic cardiomyopathy. Hum Mutat 19:560-569

Watkins H, Rosenzweig A, Hwang DS (1992) Characteristics and prognostic implications of myosin missense mutations in familial hypertrophic cardiomyopathy. N Engl J Med 326:1108-1114

Watkins H, Conner D, Thierfelder J, Jarcho JA, MacRae C, McKenna WJ, Maron BJ, Seidman JG, Seidman CE (1995a) Mutations in the cardiac myosin binding protein-C gene on chromosome 11 cause familial hypertrophic cardiomyopathy. Nat Genet 11:434-437
Watkins H, McKenna WJ, Thierfelder L, Suk HJ, Anan R, O'Donoghue A, Spirito P, Matsumori A, Moravec CS, Seidman JG (1995b) Mutations in the genes for cardiac troponin $T$ and $\alpha$ tropomyosin in hypertrophic cardiomyopathy. $\mathrm{N}$ Engl $\mathrm{J}$ Med 332:1058-1064

Watkins H, Seidman JG, Seidman CE (1995c) Familial hypertrophic cardiomyopathy: a genetic model of cardiac hypertrophy. Hum Mol Genet 4:1721-1727

Watkins H, Seidman CE, Seidman JG, Feng HS, Sweeney HL (1996) Expression and functional assessment of a truncated cardiac troponin $\mathrm{T}$ that causes hypertrophic cardiomyopathy. J Clin Invest 98:2456-2461

Wilkins BJ, Molkentin JD (2002) Calcineurin and cardiac hypertrophy: Where have we been? Where are we going? J Physiol 541:1-8

Witt CC, Gerull B, Davies MJ, Centneri T, Linke WA, Thierfelder L (2001) Hypercontractile properties of cardiac muscle fibers in a knock-in mouse model of cardiac myosin-binding protein-C. J Biol Chem 276:5353-5359

Yamauchi-Takihara K, Nakajima-Taniguchi C, Matsui H (1996) Clinical implications of hypertrophic cardiomyopathy associated with mutations in the $\alpha$-tropomyosin gene. Eur J Heart 76:6365

Yanaga F, Morimoto S, Ohtsuki I (1999) $\mathrm{Ca}^{2+}$ sensitization and potentiation of the maximum level of myofibrillar ATPase activity caused by mutations of troponin $\mathrm{T}$ found in familial hypertrophic cardiomyopathy. J Biol Chem 274:8806-8812

Yang Q, Sanbe A, Osinska H, Hewett TE, Klevitsky R, Robbins J (1998) A mouse model of myosin binding protein $\mathrm{C}$ human familial hypertrophic cardiomyopathy. J Clin Invest 102:1292-1300

Yang Q, Sanbe A, Osinska H, Hewett TE, Klevitsky R, Robbins J (1999) In vivo modeling of myosin binding protein $\mathrm{C}$ familial hypertrophic cardiomyopathy. Circ Res 85:841-847

Yu B, French JA, Carrier L, Jeremy RW, McTaggart DR, Nicholson MR, Hambly B, Semsarian C, Richmond DR, Schwartz K, Trent RJ (1998) Molecular pathology of familial hypertrophic cardiomyopathy caused by mutations in the cardiac myosin binding protein $\mathrm{C}$ gene. J Med Genet 35:205-210 